\title{
University Students' Perceptions of Social Responsibility Initiatives by Universities in Pakistan
}

\author{
Imran $\mathrm{Ali}^{1} \&$ Murad $\mathrm{Ali}^{2}$ \\ ${ }^{1}$ Department of Business Administration, Faculty of Economics \& Administration, King Abdulaziz University \\ Jeddah, Kingdom of Saudi Arabia \\ ${ }^{2}$ Department of HRM, Faculty of Economics \& Administration, King Abdulaziz University Jeddah, Kingdom of \\ Saudi Arabia \\ Correspondence: Imran Ali, Department of Business Administration, Faculty of Economics \& Administration, \\ King Abdulaziz University Jeddah, Kingdom of Saudi Arabia. E-mail: imranalinim@gmail.com
}

Received: August 2, 2016 Accepted: August 24, 2016 Online Published: September 27, 2016

doi:10.5539/jsd.v9n5p130 URL: http://dx.doi.org/10.5539/jsd.v9n5p130

\begin{abstract}
Despite of all recent developments towards the concept of corporate social responsibility (CSR), its significance is still under-emphasized. The research community still realizes the importance of CSR for the uplifting social well being and reducing vulnerabilities by increasing natural disasters. Academic institutions can also play a very important role to promote the spirit of social responsibility among student - the future business leaders. The objective of this study is to measure university student's perceptions and level of awareness towards socially responsible actions undertaken by universities in Pakistan. An exhaustive survey is conducted to collect data regarding student's perceptions towards nature and level of CSR actions performed by universities in Pakistan. The result shows that the student pays great attention to socially responsible initiatives taken by universities. Such activities also develop a socially responsible attitude among students which is very important for developing responsible business leaders. The applications and implications of this research are also discussed in detail.
\end{abstract}

Keywords: corporate social responsibility, student perceptions, responsible business leaders

\section{Introduction}

Corporate social responsibility is seen a buzzword in business literature. Researchers are exploring the perspectives of CSR related consumer, employee, investors, supply chain networks other stakeholders and organizations themselves. The concept of corporate social responsibility is gaining popularity in the 1970's when business scholars, environmental activists, consumer advocates, human right associations, and media representatives started asking about social accountability of corporations. The concern rose toward the sustainability of the environment and other natural resources mortified by massive industrial productions. Advocates of CSR also demanded that multinational are making uphill profits while degrading scarce natural resources, therefore they should sacrifice some resources for the welfare of the community and preservation of natural resources. The early contributors towards corporate social responsibility include Bowen (1953); Davis (1960, 1973); Johnson (1971); Manne (1972); Beyer (1972); Drucker (1974); Carson (1977), Carroll (1979) and Jones (1980, 1983). Carroll (1979) categorized CSR into four categories including; economic responsibilities, legal responsibilities, ethical responsibilities and discretionary responsibilities. Carroll (1979) refined the concept of corporate responsibility by integrating various definitions appeared in the literature and proposing a conceptual model to assess and identify the social responsibility philosophy of corporations. Carroll (1991) also developed a pyramid that elaborates the hierarchal progression towards corporate social responsibility. This includes fulfillment of economic responsibilities at the first step including doing profitable business, payment of handsome returns to investors, fair wages to employees and meeting financial obligations of all stakeholders. This also forms the foundation for the next levels of CSR, if any organization doing not good on the economic front, there will be no use of thinking towards next steps of CSR. Once the organization is profitable it should comply with it legal responsibilities by proving itself a law abiding citizen of the society. After fulfillment of legal responsibilities the corporations can further its social contribution by doing right just and fair and reducing harmful activities in the society. At the peak of Carroll (1991) CSR pyramid is philanthropic responsibilities, 
where organization contributes its resources to improve quality of life in the community. This includes contributing towards health, education, environment, poverty, gender discrimination, human rights, promoting sports, entertainment and arts etc.

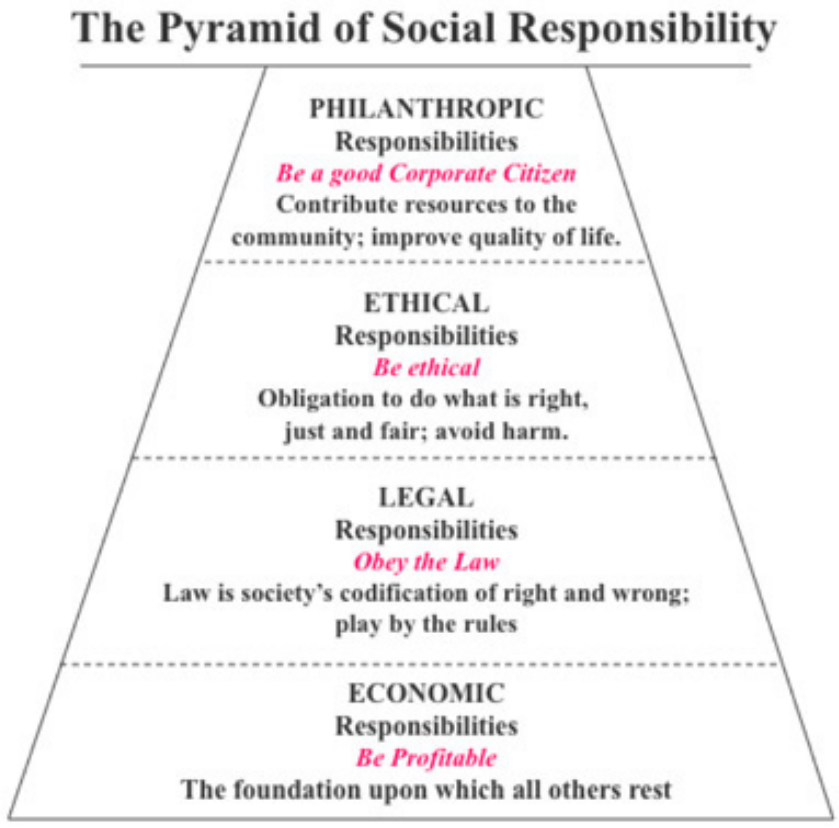

Figure 1. Carroll (1991) CSR Pyramid

The concept of Triple Bottom Line known as TBL was also introduced by John Elkington in his book titled Cannibals with Forks: the Triple Bottom Line of $21^{\text {st }}$ Century Business in 1997. The TBL concept is explained through three Ps; People, Planet and Profits. TBL approach requires organizations to contribute towards sustainable development of society, environment and economy. Corporate social responsibility is being focused by the business community at large; standards have been established for reporting CSR activities by corporations. Corporations are issuing their CSR reports alongside their annual financial reports. Corporate social performance has become an important indicator for stakeholder decision making including; consumer, investor, employee, supply chain network, money lender, government, society and media among others. Research relating to corporate social responsibility is appearing frequently in top tier research journals. Social responsibility indexes have been developed in order to rank companies in terms of their contributions towards community and environment. Likewise, corporate stakeholders have also identified themselves on the basis of their recognition of social responsibility actions as sustainable consumer, green consumer, social investor, responsible business leaders etc. The recent trends in corporate social responsibility have made it very fascinating topic for young and emerging researchers. Despite of all recent developments towards the concept of corporate social responsibility, its significance is still under-emphasized. The business community still realizes the importance of CSR for the uplifting social well being and reducing vulnerabilities to increasing natural disasters.

There is plenty of research that explores various aspects of corporate social responsibility, yet there is a lack of research regarding role of academic institutions in promoting social responsibility culture and developing responsible business managers. Current research bridges this gap by analyzing the nature of social actions undertaken by universities in Pakistan. This study will also examine the level of awareness among students towards socially responsible actions by universities in Pakistan. The reason behind choosing Pakistan for research is that there is very sparse research in this part of the world on this topic. This study will stimulate researchers, academic institutions and the business community to join hands to inculcate the culture of social responsibility in Pakistan.

\subsection{Corporate Social Responsibility in Higher Education Institutions}

The concept of social responsibility is generally associated with business corporations. However academic institutions are also playing an important role in the promotion of socially responsible culture in the society. 
Plenty of seminars and research conferences are being organized by Universities focusing on corporate social responsibility. Universities also participate actively in environmental protection programs and encourage its employees and students to participate in the voluntary program organized for community welfare and other objectives. Universities are providing financial and other resources to peruse projects related to social responsibility by students and faculty members. Knowledge related to corporate social responsibility is generated, published and disseminated by higher education institutions. Research Centers and Chairs have been devoted by universities to continuously work to the promotion of corporate social responsibility in different perspectives. Universities are teaching their students the significance of corporate social responsibility and make them realize the benefits that can be gained from practicing it.

Numbers of studies have stressed the significance of higher academic institutions in teaching and training ethical and responsible actions to students across disciplines to quote few Hansen (2006) also highlighted that higher academic institutions should ethics and responsibility in their training programs. Hansen (2006) also pointed out that ethics and responsibility aspects are rarely included in studying programs educating engineers and scientists. Leitao and Silva (2007) also proposed that universities can integrate analysis, implementation and assessment of CSR policies, also universities can play strategic role in developing policies related to CSR initiatives. Pollock et al. (2009) indicated that ineffective governance, complex disciplinary boundaries, traditionally designed curriculums, lack of social responsibility vision restricts the higher education institution's role towards contributing to sustainable development of society. Jabbour (2010) argues that universities can bring significant environmental effect in the society, by teaching and training students to behave responsibly. Nejati et al. (2010) noted that universities promote environmental awareness among their employees and students. Burcea and Marinescu (2011) examined the perceptions of university students towards CSR actions of University and found that students attach importance to CSR at an academic level and universities should involve the student's maximum to develop their socially responsible attitude. Ahmed (2012) examined the role of universities to drive CSR in the society in the context of Malaysia. Dahan and Senol (2012) hold that universities must be having strong social responsibility policies implemented internally well supported by top management to teach students for adopting socially responsible behavior. Kaul and Smith (2012) highlighted the role of Universities in communicating and understanding CSR philosophy among students, employees, business leaders. They also proposed a model that helps in greater understanding of social responsibility. This seven step model of CSR progresses from family responsibility of individuals, to work responsibilities, to self responsibilities, for spiritual and religious responsibilities to responsibility towards global issues and finally, universal responsibilities.

\section{Research Design}

\subsection{Sample}

This study examines the student's perceptions towards social responsibility of Universities in Pakistan. The study is exploratory in nature based on primary data collected from students studying in public and private sector Universities of Pakistan. The population in this study contains the university students' studying in various universities of Pakistan. For sampling purposes, 20 higher education institutions have been selected from Pakistan for data collection. Structured close ended questionnaires were sent to various departments of universities to ensure participations across the academic disciplines. The respondents from diverse backgrounds participated in this study, including gender, academic discipline, the level of the study program and various institutions across Pakistan. A total of 500 questionnaires were sent to 20 universities out of which 315 usable questionnaires were received leaving a response rate of $63 \%$ which is quite acceptable in social sciences.

\subsection{Measures}

The instrument to measure student's perception towards nature and level of social responsibility initiatives undertaken by higher education institutes is adopted from Burcea and Marinescu (2011) who conducted quite similar type of study in the context of Romania. However, to make this study more meaningful more questions have been added to existing instruments. The new questions inquire about the vision of CSR and environmental sustainability among university top management, and formal communication of this vision to employees, students and other stakeholders of universities. It also includes the depiction of CSR vision in the policies and procedures of higher education institutions and the recognition of socially responsible contributions from employees, especially students by the university administration. The question relating to the arrangement of CSR related seminars, conferences, lectures and other special events is also incorporated the measurement instrument to gauge the activeness level among higher education institutions of Pakistan. Each question is this study is measured on an appropriate scale in order to have better feedback from respondents. Demographic information important for this study is also asked in this instrument to add more value to research. 


\subsection{Procedure}

The data collected through structured survey questionnaires is entered into SPSS sheet for further analysis purposes. The reliability analysis is also performed to test the appropriateness of data for further examinations. Simple descriptive analyses are performed in this study to report the results of various questions. The responses are also presented in figures and tables to make our analysis more interesting and meaningful. The latest version of SPSS is used for analysis purposes in this study. The Independent sample T-test and one way ANOVA analysis are used to calculate means and their comparisons in different demographic profiles. The Independent T-test is used where there are two categories of demographic features for example male and female or other responses measured on dichotomous scale. Whereas one way ANOVA is used to calculate when the categories are more than two for instance age, income level, education and the like.

\section{Result and Discussion}

The analysis of data expresses interesting insights towards environmental concerns held by universities and students. A brief summary of descriptive analysis is presented in this section. The results indicate how both students and universities contribute towards various environmental and social issues. Table 1 provides the sample composition used in this study, it depicts the fair number of participants contributed in this study. The sample composition contains $77 \%$ male and $23 \%$ female, due to relatively less participation of female in university education. A large number of $81 \%$ students participated from undergraduate programs across various disciplines and 19\% participated from post graduate programs. In terms of academic disciplines, large number of students participated from business administration (29\%), arts and humanities includes (17\%), computer sciences $(21 \%)$, basic and applied sciences $(18 \%)$ and medical sciences $(15 \%)$. The objective of collection of data from across disciplines university students is to examine the CSR awareness in non-business students. The sample composition also constitutes $64 \%$ respondent students from urban residential background whereas $36 \%$ from rural background as shown in Table1.

Table 1. Sample composition

\begin{tabular}{|c|c|}
\hline Characteristic & Sample percentage $(N=315)$ \\
\hline \multicolumn{2}{|l|}{ Gender } \\
\hline Male & $77 \%$ \\
\hline Female & $23 \%$ \\
\hline \multicolumn{2}{|l|}{ Academic Program } \\
\hline Undergraduate & $81 \%$ \\
\hline Post graduate & $19 \%$ \\
\hline \multicolumn{2}{|l|}{ Academic Discipline } \\
\hline Business administration & $29 \%$ \\
\hline Arts and humanities & $17 \%$ \\
\hline Computer sciences & $21 \%$ \\
\hline Basic and applied sciences & $18 \%$ \\
\hline Medical sciences & $15 \%$ \\
\hline \multicolumn{2}{|l|}{ Background } \\
\hline Urban & $64 \%$ \\
\hline Rural & $36 \%$ \\
\hline
\end{tabular}

The first question on survey is related to university's voluntary participation in environmental protection program. Table 2 indicates that $40.4 \%$ students report that university participates in voluntary environmental protection programs. However, $31.2 \%$ students say university does not participate in such programs. Furthermore, 28.4\% students report their lack of knowledge about such matters. On overall results are not satisfactory, as majority of students either do not participate in the university is not eager to participate in environmental protection programs on a voluntary basis. 
Table 2. Participation in environment related activities

\begin{tabular}{lc}
\hline Answer & Relative Frequency (\%) \\
\hline Yes & 40.4 \\
No & 31.2 \\
Don't Know & 28.4 \\
Total & 100 \\
\hline
\end{tabular}

The third question is related to the type of environmental protection program. Approximately, $18 \%$ respondents indicate that university participates in park development, therefore contributing in environmental protection programs. The university also contributes to environment by tree plantation, as responded by $32 \%$. Similarly, $10 \%$ students reported that university participates in flower plantation. $40 \%$ students responded that university carries out activities related to recycling waste products. In summary, the answers to this question suggest that the university takes a variety of initiatives towards environmental protection.

Table 3. Type of environmental protection

\begin{tabular}{lc}
\hline Answer & Relative Frequency (\%) \\
\hline Park Development & 18 \\
Tree Plantation & 32 \\
Flower Plantation & 10 \\
Recycling waste & 40 \\
Total & 100 \\
\hline
\end{tabular}

The fourth question in the survey asks about honesty in procedures related to contracts. There are $23 \%$ respondents who believe that honesty is kept while signing contracts to protect benefits of various stakeholders. $42 \%$ students believe that honesty in procedures in maintained partially, hence not it suggest that either all contracts are not carried out honestly or all stakeholders are not taken care of at the time of signing contracts. Approximately, $12 \%$ respondents believe that university is unfair in signing contracts and does not take care of all concerned stakeholders. There is a big chunk (33\%) of students who report to be unaware about quality of contracts undertaken by university.

Table 4. Quality and honesty in procedures at KSU

\begin{tabular}{lc}
\hline Answer & Relative Frequency (\%) \\
\hline Yes & 23 \\
Partially & 42 \\
No & 12 \\
DK & 33 \\
Total & 100 \\
\hline
\end{tabular}

Question five is related to academic quality improvement as it asks students about value of their advice in designing courses. $43 \%$ students report that university seeks their advice in matters of quality improvement related to academic courses. $34 \%$ students disagree and report that the university does not take their advice in designing courses and seminars. $22.5 \%$ students indicate that they are not aware of such initiatives where university seeks student advice or not. 
Table 5. Consultation with students

\begin{tabular}{lc}
\hline Answer & Relative Frequency (\%) \\
\hline Yes & 43.0 \\
No & 33.8 \\
DK & 22.5 \\
Total & 100 \\
\hline
\end{tabular}

Question number 6 is also related to student perception of fairness in problems faced by students. Only $16 \%$ students believe that the university administration is always fair in addressing student problems. $46 \%$ students have mixed feeling, and their belief that university sometimes has fair treatment of students' issues and sometimes student affairs are not addressed on merit. 19\% students report that it is a rare chance that university administration solves student matters on fair terms. $6 \%$ student in survey did not have their say in this question. A closer look at the answer pattern suggests that students do not feel comfortable with the procedures in which their matters are managed. There is a clear indication that students feel some biases in the way administration deals with their problems.

Table 6. Fair system of complaints

\begin{tabular}{cc}
\hline Answer & Relative Frequency (\%) \\
\hline Yes Always & 15.9 \\
Sometimes Yes Sometimes No & 46.4 \\
Rarely & 19.2 \\
Not at all & 11.9 \\
Don't Know & 6.0 \\
Total & 100 \\
\hline
\end{tabular}

Question seven is related to university cooperation with other institutes for improvement in education quality. 42.4\% students report that the university has cooperation agreements with other institutes, $43.7 \%$ students believe that university partially in engaged in cooperation agreements with other institutes to improve education quality. Only $13.2 \%$ students believe that university is not engaged in cooperation agreements with professional institutes. On an aggregate basis, it is concluded that the university has established network with professional institutes to improve education quality.

Table 7. Cooperation with other organizations

\begin{tabular}{lc}
\hline Answer & Relative Frequency (\%) \\
\hline Yes & 42.4 \\
Partially & 43.7 \\
No & 13.2 \\
Total & 100 \\
\hline
\end{tabular}

Question eight deals with students' perception related to efforts in solving community problems. There are two dimensions to this question, first is related to student participation in community related activities, whereas the second is related to finances devoted to solve community problems. For the first part, $10.6 \%$ students indicate that the university encourages them to a large extent in participation for community related problems. $28.5 \%$ also believe that university largely encourages them to participate in community related problems. $35.1 \%$ students' belief that there is limited encouragement from university to participate in community care activities. Only $5.3 \%$ responded reported that there is little if university encourages in conducting programs for community help. Around $20 \%$ students do not know about programs related to community care. 
Table 8. Encourage students to participate in CSR related activities

\begin{tabular}{lc}
\hline Answer & Relative Frequency (\%) \\
\hline To a large extent & 10.6 \\
Largely & 28.5 \\
Small extent & 35.1 \\
Very small extent & 5.3 \\
DK & 19.9 \\
Total & 100 \\
\hline
\end{tabular}

The second part is related to community support in financial terms. The response patterns as reported in Table 9 suggests $10.6 \%$ students believe, to a large extent, that university provides financial support in community's problems. $33 \%$ state that largely, university financial contributions are related to community problems. $25.5 \%$ students indicate that the university makes financial contribution to community problems in small context. $17.2 \%$ students suggest that their university contributes only to a small extent, in terms of finances for community improvement programs. There are only $13.2 \%$ students who indicate lack of knowledge about a community program.

Table 9. University contributes financially to CSR activities

\begin{tabular}{lc}
\hline Answer & Relative Frequency (\%) \\
\hline To a large extent & 10.6 \\
Largely & 33.1 \\
Small extent & 25.2 \\
Very small extent & 17.2 \\
DK & 13.2 \\
Total & 100 \\
\hline
\end{tabular}

Next question pertains to university values and commitments towards stakeholders. There are three components to this question, commitment towards, employees, students and business community. There are $27.2 \%$ students which indicate that the university has positive values and commitment to the well-being of employees. $51 \%$ respondents partially trust on values and commitment related to employee benefits. Around $12 \%$ respondents indicate that the university does not possess values and commitment to employee welfare. There are $9.3 \%$ respondents who indicate that they are not knowledgeable in this regard as reported in Table 10.

Table 10. University commitment towards employees

\begin{tabular}{lc}
\hline Answer & Relative Frequency (\%) \\
\hline Yes & 27.2 \\
Partially & 51.0 \\
No & 11.9 \\
DK & 9.3 \\
Total & 100 \\
\hline
\end{tabular}

In terms of commitment to university students, Table 11 shows that $33.1 \%$ respondents indicate that the university is committed towards students. $37.7 \%$ respondents indicate that the university is partially committed to student welfare. $22.5 \%$ students' belief that university is not committed to its students' welfare. Whereas $6 \%$ students indicate have no knowledge about this factor. 
Table 11. Commitment towards students

\begin{tabular}{lc}
\hline Answer & Relative Frequency (\%) \\
\hline Yes & 33.1 \\
Partially & 37.7 \\
No & 22.5 \\
DK & 6.0 \\
Total & 100 \\
\hline
\end{tabular}

For commitment towards the business community, 36.4\% students indicate that the university is committed towards welfare of the business community. $32.5 \%$ feel that university is partially committed towards value addition for the business community. A mere $5 \%$ respondent agrees otherwise, suggesting that the university is not committed to the business community. A large chunk of respondents, $25 \%$, refrain to be knowledgeable about this issue. On an aggregate basis, it is assumed that the university is committed to the business community.

Table 12. Commitment towards business community

\begin{tabular}{lc}
\hline Answer & Relative Frequency (\%) \\
\hline Yes & 36.4 \\
Partially & 32.5 \\
No & 5.3 \\
DK & 25.2 \\
Total & 100 \\
\hline
\end{tabular}

Question 10 seeks response regarding quality of CSR programs. 7.3\% students report that university CSR programs are very good; however $28.5 \%$ are not highly appreciative, they feel that these initiatives are only good enough. $35.1 \%$ response reflects that university's CSR initiatives are "So So" which means that these CRS related efforts represent only an average level of satisfaction. A small fragment of respondents, $4 \%$ students, indicate that there CSR initiatives of university are bad. Similarly, $4.6 \%$ respondents believe that these initiatives are very bad, hence indicating that they are completely dissatisfied from university's CSR activities. A large number of students don't know about the achievement of university towards socially responsible actions, which also shows lack of communication in this regard.

Table 13. Degree of achievement by University

\begin{tabular}{lc}
\hline Answer & Relative Frequency (\%) \\
\hline Very Good & 7.3 \\
Good & 28.5 \\
So so & 35.1 \\
Bad & 4.0 \\
Very Bad & 4.6 \\
DK & 19.9 \\
Total & 100 \\
\hline
\end{tabular}

The eleventh question indicates sustainable growth environment through CSR. Data shows that $41 \%$ students believe that the university has a clear vision regarding sustainable economic growth. On the other hand $22 \%$ respondents believe that the university does not have a clear vision for sustainable economic growth through CSR activities. $36.4 \%$ students are not knowledgeable in this regard. 
Table 14. University vision of CSR

\begin{tabular}{lc}
\hline Answer & Relative Frequency (\%) \\
\hline Yes & 41.21 \\
No & 28.9 \\
DK & 36.4 \\
Total & 100 \\
\hline
\end{tabular}

Communication of CSR vision to employees, students and other stakeholders is the next important question. The data presented in Table 15 reveal varying responses among respondents about communication of CSR vision. There are $37 \%$ respondents who feel that university is successfully accomplishing communication of its vision for CSR. However, $22.5 \%$ think that the university lacks in proper communication of its vision related to CSR and economic stability. A large portion of response 39.7\%, indicate having no knowledge regarding communication of university vision for sustainable economic growth.

Table 15. Clear communication of CSR vision

\begin{tabular}{cc}
\hline Answer & Relative Frequency (\%) \\
\hline Yes & 44.1 \\
No & 22.5 \\
DK & 39.7 \\
Total & 100 \\
\hline
\end{tabular}

University policies and practices regarding CSR are addressed in the next question. There are $17.2 \%$ participants who indicate that the university has policies and practices concerned with CSR. Whereas $45.7 \%$ report that the university partially possesses policies and practices for CSR. Only 4\% survey participants represent that there is no policy regarding CSR on the part of universities. Around $32 \%$ responses are not knowledgeable about university policies for social responsibility as depicted in Table 16.

Table 16. Depiction of CSR in policies and procedures

\begin{tabular}{lc}
\hline Answer & Relative Frequency (\%) \\
\hline Yes & 17.2 \\
Partially & 52.7 \\
No & 4.6 \\
DK & 31.8 \\
Total & 100 \\
\hline
\end{tabular}

The next question in the survey is regarding active participation of university inactions and programs that are targeted towards CSR. For example a university can conduct seminars, workshops, conferences and lectures for increasing awareness of CSR. The results indicate 33\% agreement among respondents, that university is engaged in activities like seminars and conferences for corporate social responsibility. Moreover, $27.2 \%$ respondents indicate that the university is not actively participating in CSR. Lastly, 39\% believe that they are not knowledgeable for university participation in corporate social responsibility. 
Table 17. CSR conferences and seminars

\begin{tabular}{lc}
\hline Answer & Relative Frequency (\%) \\
\hline Yes & 40.1 \\
No & 27.2 \\
DK & 39.1 \\
Total & 100 \\
\hline
\end{tabular}

Question 15 relates to the perception held by university management regarding CSR initiatives taken by its employees and students. A high recognition by university for such employees and students will be a source of encouragement and will build up a culture of social support. The results reveal that $23 \%$ students perceive that a university always encourages employee and student efforts for CSR. On the other hand, $51 \%$ students believe that the university only partially encourages student and employee CSR efforts. There is $12.7 \%$ response suggesting that the university does not encourage societal contributions. $12 \%$ respondents reveal that they do not have any knowledge in this matter.

Table 18. Recognition of CSR by University

\begin{tabular}{lc}
\hline Answer & Relative Frequency (\%) \\
\hline Yes & 23.3 \\
Partially & 52.0 \\
No & 12.7 \\
DK & 12.0 \\
Total & 100 \\
\hline
\end{tabular}

\section{Conclusion and Recommendations}

The objective of this study was to examine the university students' perceptions of CSR and the socially responsible initiatives undertaken by higher education institutions in Pakistan. The findings of the study show that relatively fewer students responded that their university actively participates in environmental issues. The majority of students believe that there is lack of fair system of obtaining and addressing students' complaints in their universities. Not an encouraging number of students believe that university contributes financially towards CSR activities, which should also be a matter of concern for university administration. There is a lack of clear vision and depiction of socially responsible actions in the policies and procedures in the universities in Pakistan. There is also lack of organizing seminars, workshops and conferences related to corporate social responsibilities in Pakistani universities. The study proposes that universities should increase their socially responsible initiatives to inspire students and train them to do the same in their professional life. The universities should ensure honesty in its procedures related to signing and completion of contracts with various stakeholders. The universities should develop a fair system of filing complaints by the students, which should be dealt carefully and proper feedback should be communicated to the concerned stakeholders to increase their level of satisfaction from university services. The universities should make financial contributions towards CSR activities and communicate it in their electronic and print resources to publicize at large scale to inspire their students. The universities should also exhibit higher level of commitment towards their students, employees, and community to strengthen their bonds with these stakeholders. The universities must be having clear vision of CSR, depicted very effectively in their policies and procedures across all facets and at various levels. The contents related to social responsibility should be included in the curriculum across all disciplines in higher education institutions; it should not be limited to business studies only. Finally, there should be more seminars and conferences related to corporate social responsibility and its application across various disciplines. This will sensitize students towards this important issue and will train them to adopt socially responsible attitude in their professional life in respective organizations.

\section{References}

Ahmed, J. (2012). Can a university act as a corporate social responsibility (CSR) driver? An analysis. Social Responsibility Journal, 8(1), 77-86. http://dx.doi.org/10.1108/17471111211196584 
Beyer, R. (1972). The 'Bottom Line' is no longer where it's at; an accounting executive lists five considerations for corporate social responsibility. New York Times Magazine, September 24, 1972, Sunday Section: Business and Finance, pp F14.

Bowen, H. R. (1953). Social responsibilities of the businessman. Harper \& Row, New York.

Brown, E., \& Cloke, J. (2009). Corporate social responsibility in higher education. ACME: An International E-Journal for Critical Geographies, 8(3), 474-483.

Burcea, M., \& Marinescu, P. (2011). Students perceptions at corporate social responsibility at the academic level. Case study: The Faculty of Public Administration and Business, University of Bucharest. Amfiteatru Economics, 8(29), 207-220.

Carroll, A. B. (1979). A three-dimensional conceptual model of corporate performance. Academy of Management Review, 4, 497-505.

Carroll, A. B. (1991). The pyramid of corporate social responsibility: towards the modal management of organizational stakeholders. Business Horizons, 39-48. http://dx.doi.org/10.1016/0007-6813(91)90005-G

Carson, D. (1977). Point of View; Companies as Heroes? Bah! Humbug!! New York Times Magazine, December 25, 1977, Sunday, Section: Business \& Finance, Page 94.

Dahan, G. H., \& Senol, I. (2012). Corporate social responsibility in Higher education institutions: Istanbul Bilgi University case. American International Journal of Contemporary Research, 2(3), 95-103.

Davis, K. (1960). Can business afford to ignore corporate social responsibility? California Management Review, 2, 70-76. http://dx.doi.org/10.2307/41166246

Davis, K. (1973). The case for and against business assumption of social responsibility. Academy of Management Journal, 16, 312-322. http://dx.doi.org/10.2307/255331

Drucker, P. F. (1974). Management: tasks, responsibilities, practices. New York: Harper \& Row.

Elkington, J. (1997). Cannibals with Forks: the Triple Bottom Line of $21^{\text {st }}$ Century Business.

Hansen, T. B. (2006). Academics and social responsibility of scientists. Journal on Science and World Affairs, 2(2), 71-92.

Jabbour, C. J. C. (2010). Greening of business schools: a systematic view. International Journal of Sustainability in Higher Education, 11(1), 49-60. http://dx.doi.org/10.1108/14676371011010048

Johnson, H. L. (1971). Business in Contemporary Society: Framework and Issues. Belmont, Ca: Wadsworth.

Jones, T. M. (1980). Corporate social responsibility revisited, redefined. California Management Review, 22(2), 59-67. http://dx.doi.org/10.2307/41164877

Jones, T. M. (1983). An integrating framework for research in business and society: A step toward the elusive paradigm. Academy of Management Review, 8(4), 559-565. http://dx.doi.org/10.2307/258257

Kaul, M., \& Smith, J. (2012). Exploring the nature of responsibility in Higher education. Journal of Global Responsibility, 3(1), 1-10.

Leitao, J., \& Silva, M. J. (2007). CSR and social marketing: what is the desired role for universities in fostering public policies? Retrieved April 16, 2012, from http://mpra.ub.uni-muenchen.de/2954/1/MPRA_paper_2954.pdf

Manne, G. H. (1972). Responsibility; the social role of business could lead to market's extinction. New York Times Magazine, February 20, 1972, Sunday Section: Bus. Fin. F16.

Nejati, M., Salamzadeh, Y., \& Sharafi, F. F. (2010). Environmental sustainability: a study of world leading universities. Proceedings of International Conference on Environmental Research and Technology, Malaysia: $175-178$.

Pollock, N., Horn, E., Costanza, R., \& Sayre, M. (2009). Envisioning helps promote sustainability in academic: a case study at the University of Vermont. International Journal of Sustainability in Higher Education, 10(4), 343-353. http://dx.doi.org/10.1108/14676370910990693

\section{Copyrights}

Copyright for this article is retained by the author(s), with first publication rights granted to the journal.

This is an open-access article distributed under the terms and conditions of the Creative Commons Attribution license (http://creativecommons.org/licenses/by/4.0/). 